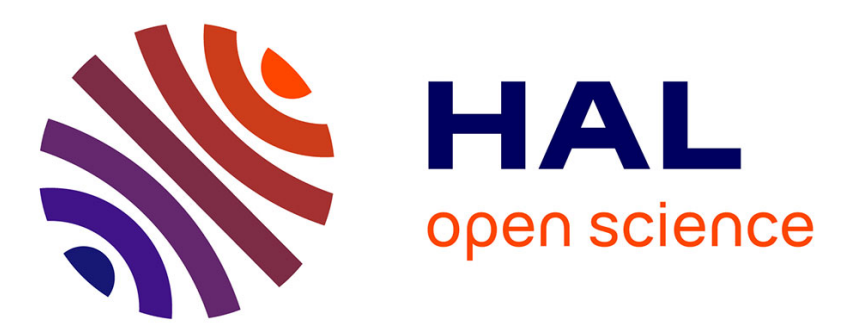

\title{
In Situ Ellipsometry Study of the Early Stage of ZnO Atomic Layer Deposition on In 0.53 Ga 0.47 As
}

\author{
Evgeniy V Skopin, Jean-Luc Deschanvres, Hubert Renevier
}

\section{To cite this version:}

Evgeniy V Skopin, Jean-Luc Deschanvres, Hubert Renevier. In Situ Ellipsometry Study of the Early Stage of ZnO Atomic Layer Deposition on In 0.53 Ga 0.47 As. physica status solidi (a), 2020, 217 (8), pp.1900831. 10.1002/pssa.201900831 . hal-03103267

\section{HAL Id: hal-03103267 https://hal.science/hal-03103267}

Submitted on 8 Jan 2021

HAL is a multi-disciplinary open access archive for the deposit and dissemination of scientific research documents, whether they are published or not. The documents may come from teaching and research institutions in France or abroad, or from public or private research centers.
L'archive ouverte pluridisciplinaire HAL, est destinée au dépôt et à la diffusion de documents scientifiques de niveau recherche, publiés ou non, émanant des établissements d'enseignement et de recherche français ou étrangers, des laboratoires publics ou privés. 


\title{
In situ ellipsometry study of the early stage of $\mathrm{ZnO}$ Atomic Layer Deposition on $\ln _{0.53} \mathrm{Ga}_{0.47}$ As
}

\author{
Evgeniy V. Skopin ${ }^{*}$, , Jean-Luc Deschanvres ${ }^{1}$, and Hubert Renevier ${ }^{1}$ \\ ${ }^{1}$ Univ. Grenoble Alpes, CNRS, Institute of Engineering Univ. Grenoble Alpes (Grenoble-INP), LMGP, 38000 Grenoble, France
}

Key words: Atomic Layer Deposition, $\mathrm{ZnO}$, InGaAs, ellipsometry, oxides, initial growth, growth delay, substrate inhibited growth of type II

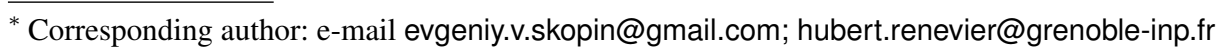

We report on the initial stages of ZnO Atomic Layer Deposition (ALD) on $\operatorname{In}_{0.53} G_{0.47} A s$ (InGaAs), studied by monitoring the $\mathrm{ZnO}$ film thickness in situ with spectroscopic ellipsometry. Using diethylzinc (DEZn) and water, at a substrate temperature equal to $120^{\circ} \mathrm{C}$, we found the presence of two different $\mathrm{ZnO}$ growth regimes prior to the steady growth: a slow ZnO nucleation on InGaAs, 0.005 nm.cy ${ }^{-1}$ (growth delay), then a substrate inhibited growth of type II. Increasing the DEZn injection time, the growth delay shortened from 30 cycles down to 3 cycles, concomitantly the steady growth rate increased from 0.18 to $0.23 \mathrm{~nm} . \mathrm{cy}^{-1}$. The DEZn residence time and pressure increase during the first ALD cycle, allowing to suppress the growth delay, instead, no change is observed when performing the same experiment with water. Atomic Force Microscopy (AFM) images showed that the InGaAs surface roughened after the first cycle with a long DEZn pulse and residence time. The rough surface is likely at the origin of the growth delay elimination.

Copyright line will be provided by the publisher

1 Introduction $\operatorname{In}_{x-1} \mathrm{Ga}_{x}$ As ternary alloy is a semiconductor, with a direct bandgap and high charge carrier mobility, which is widely used in microelectronics [1]. By varying the In/Ga ratio, the face-centered cubic lattice parameter changes from $0.565 \mathrm{~nm}$ to $0.606 \mathrm{~nm}$ and the bandgap energy from $1.414 \mathrm{eV}(\mathrm{x}=1)$ to $0.354 \mathrm{eV}$, respectively $(x=0)[2-4]$. Thus, this material is widely used in infrared electronics [5]. Thanks to its high carrier mobility, $\mathrm{In}_{x-1} \mathrm{Ga}_{x}$ As can be utilized as a channel material in Metal Oxide Semiconductor Field Effect Transistor (MOSFET) $[6,7]$. In this case, a possible issue is the metal Fermi level pinning at the Metal- $\operatorname{In}_{x-1} \mathrm{Ga}_{x}$ As interface, leading to an increase of the Metal-Semiconductor contact resistance [8].

However, insertion of an ultra-thin oxide layer in between metal and $\operatorname{In}_{x-1} \mathrm{Ga}_{x}$ As can suppress the metal Fermi level pinning [9]. $\mathrm{ZnO}$ is one of the candidates for the ultra-thin oxide layer [10], considering that the thickness of this layer should be close to $1 \mathrm{~nm}$ in order to optimize the tunneling current flow [11].
One method, which allows controlling of thin film thickness and conformality at the nanometer scale is Atomic Layer Deposition (ALD) [12-14]. Thermal ALD is a Chemical Vapor Deposition (CVD) technique, based on self-limited chemical reactions on the surface heated up to a constant temperature. ALD process consists of sequential cycles. One cycle is a time-sequenced injection of four gases inside the reactor chamber: a metalorganic precursor (DEZn), a purge with inert gas $\left(\mathrm{N}_{2}\right)$, an oxidant $\left(\mathrm{H}_{2} \mathrm{O}\right)$, and a purge. Most generally, thermal ALD provides ideal layer by layer growth with a steady growth rate.

By using synchrotron radiation techniques for monitoring of $\mathrm{ZnO}$ ALD on $\mathrm{In}_{0.53} \mathrm{Ga}_{0.47}$ As (hereinafter InGaAs) $[15,16]$, we put in evidence that the initial $\mathrm{ZnO}$ growth on InGaAs is very different from the ideal layer by layer $\mathrm{ZnO}$ growth on $\mathrm{ZnO}$. We demonstrated the presence of two successive growth regimes preceding the steady $\mathrm{ZnO}$ ALD.

In the present study, we report on the influence of $\mathrm{Zn}$ precursor (diethylzinc) and oxidant (water) injection time or concentration on the $\mathrm{ZnO}$ initial growth stages on InGaAs. For monitoring in situ the initial stages of growth, 
we have implemented spectroscopic ellipsometry [17] on our custom-build reactor, which is used also for X-ray studies $[18-20,15]$. Provided that the appropriate model for calculating the thin film optical parameters is known, spectroscopic ellipsometry allows to monitor the thickness as a function of the number of cycles in situ and, most importantly, to provide insights into the growth process.

2 Experiment We used commercial InP substrates with $270 \mathrm{~nm}$ thick InGaAs layer grown by molecular beam epitaxy (III-V Lab, Paris, France). To remove possible oxides on the InGaAs surface [21], the InGaAs substrates were etched in $4 \mathrm{M} \mathrm{HCl}$ solution for $5 \mathrm{~min}$, then substrates were rinsed in water for $30 \mathrm{~s}$, and dried with nitrogen flow. Then, the substrate was immediately uploaded into the ALD reactor chamber and annealed at $200^{\circ} \mathrm{C}$ for $30 \mathrm{~min}$ (to evaporate atomic As). After this, we performed $\mathrm{ZnO}$ deposition on InGaAs while controlling the thickness by spectroscopic ellipsometry.

To monitor in situ the thickness of the $\mathrm{ZnO}$ thin film, we used Film Sense FS-1 ${ }^{T M}$ Banded Wavelength Ellipsometer and FS-1 software for thickness calculation [22]. The FS- $1^{T M}$ Ellipsometer records the data across 4 discrete wavelengths in the visible spectrum: $465 \mathrm{~nm}$ (blue), $525 \mathrm{~nm}$ (green), 580nm (yellow), and 635nm (red). Post growth sample surface morphology was studied ex situ by Atomic Force Microscopy (AFM), using a Dimension Icon Bruker $^{T M}$ microscope.

\section{Results}

3.1 In situ thickness monitoring One $\mathrm{ZnO}$ ALD cycle contains four steps of sequential gas injections into the reactor chamber: injection of a $\mathrm{Zn}$ precursor, a purge of the reactor chamber with inert gas, injection of an oxidant, and again purge. We used $\mathrm{Zn}\left(\mathrm{C}_{2} \mathrm{H}_{5}\right)_{2}$ (DEZn) and water as a precursor and oxidant, and nitrogen $\left(\mathrm{N}_{2}\right)$ inert gas for purging the reactor. For all samples, the flows of DEZn, water, and $\mathrm{N}_{2}$ were $5 \mathrm{sccm}, 2.6 \mathrm{sccm}$, and $1000 \mathrm{sccm}$, respectively. The $\mathrm{N}_{2}$ purging time after DEZn or water injection was $45 \mathrm{~s}$, instead, DEZn and water injection times were varied. The substrate temperature during growth was $120^{\circ} \mathrm{C}$ for all samples (this temperature is inside the temperature ALD window for DEZn/water $\mathrm{ZnO}$ ALD [23,24]). The $\mathrm{ZnO}$ thickness was monitored in situ by ellipsometry during the ZnO ALD. To calculate the $\mathrm{ZnO}$ layer thickness, we modeled the sample by the $\mathrm{ZnO}(\# \mathrm{~nm}) / \mathrm{InGaAs}(270 \mathrm{~nm}) / \mathrm{InP}($ substrate) stack. Optical coefficients for $\mathrm{ZnO}$, InGaAs layer, and InP substrate were fixed. To determine the refractive indexes $v s$. wavelength $\lambda$ of the different materials, we used the Cauchy equation $[25,22]$ :

$$
n(\lambda[n m])=n_{633 n m}+n_{\text {slope }}\left(\left(\frac{1000}{\lambda}\right)^{2}-\left(\frac{1000}{633}\right)^{2}\right),
$$

where $n_{633 n m}$ is the refractive index for HeNe laser wavelength $(633 \mathrm{~nm}) ; n_{\text {slope }}$ is a constant. The $n_{633 n m}$ and $n_{\text {slope }}$ values were equal to 3.54 and 0.21 for InP [26], 3.79 and 0.25 for InGaAs [27], and 1.99 and 0.03 for $\mathrm{ZnO}$ [28], respectively. The angle of incidence was fixed and equal to $35^{\circ}$ with respect to the sample surface normal. The Brewster's angles for InP [26], InGaAs [27], and $\mathrm{ZnO}$ [28] are $74.266^{\circ}, 75.370^{\circ}$, and $63.306^{\circ}$, respectively. $\mathrm{ZnO}$ thickness measurements (real-time approximation) were carried out with a $1 \mathrm{~s}$ integration time. No surface and interface roughnesses were used.

Figure 1 shows an example of the thickness change during one ALD cycle with injection times equal to $80 \mathrm{~s}(\mathrm{DEZn}) / 45 \mathrm{~s}\left(\mathrm{~N}_{2}\right) / 40 \mathrm{~s}\left(\mathrm{H}_{2} \mathrm{O}\right) / 45 \mathrm{~s}\left(\mathrm{~N}_{2}\right)$, respectively. An

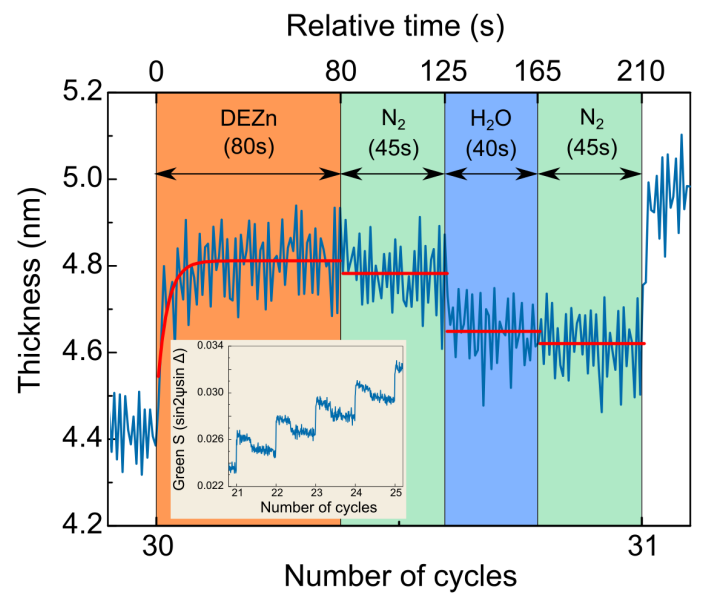

Figure $1 \mathrm{ZnO}$ thickness determined by ellipsometry model as a function of the number of cycles, example for one ALD cycle. One ALD cycle includes DEZn injection (80s, orange region), water injection (40s, blue region), and $\mathrm{N}_{2}$ purges ( $45 \mathrm{~s}$, green regions). Inset shows raw ellipsometry data of $S=\sin 2 \Psi \sin \Delta$ versus the number of cycles measured for the same sample.

example of raw data $S(S=\sin 2 \Psi \sin \Delta) v s$. number of cycles for this sample is shown in the inset of Figure $1(\Psi$ and $\Delta$ are the amplitude ratio and phase angle, determined as $R_{p} / R_{s}=\tan \Psi e^{i \Delta}$, where $R_{p}$ and $R_{s}$ are the complex Fresnel reflection coefficients for p- and s-polarized light [17]). As Figure 1 shows, the thickness noise amplitude is about $0.05 \mathrm{~nm}$ (the noise level decreases, for instance, by increasing acquisition time). When the DEZn injection begins, the layer thickness abruptly increases and then reaches a constant value (orange area in Figure 1). For the experimental data visualization, the experimental thicknesses were fitted by a sigmoidal function in the DEZn injection area (red line). During $\mathrm{N}_{2}$ purging after the DEZn injection, a slight thickness decrease is observed (green left area, the red lines correspond to the average thickness). When water is injected, a clear thickness decrease is observed (blue area). During $\mathrm{N}_{2}$ purge after water injection, the grown layer thickness slightly decreases (green area on the right). 
Figure 2(a) shows the measured thickness vs. cycle number during $\mathrm{ZnO}$ ALD for a sample grown with injection times equal to $5 \mathrm{~s}(\mathrm{DEZn}) / 45 \mathrm{~s}\left(\mathrm{~N}_{2}\right) / 10 \mathrm{~s}\left(\mathrm{H}_{2} \mathrm{O}\right) / 45 \mathrm{~s}\left(\mathrm{~N}_{2}\right)$, respectively. At the beginning of growth (regime I), a thick-

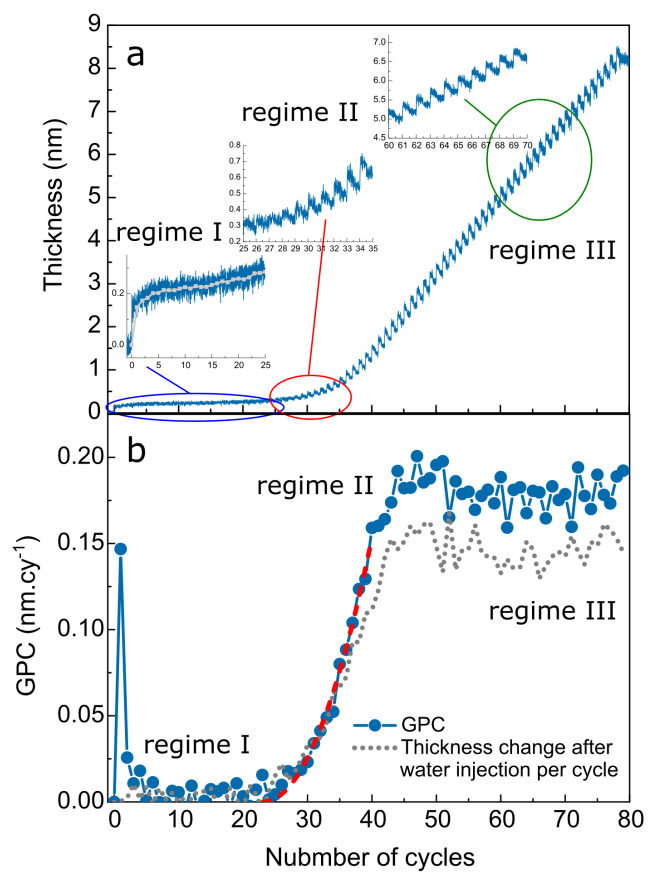

Figure $2 \mathrm{ZnO}$ Thickness (a) and GPC (b) as a function of the number of cycles measured for a sample grown with injection times equal to $5 \mathrm{~s}(\mathrm{DEZn}) / 45 \mathrm{~s}\left(\mathrm{~N}_{2}\right) / 10 \mathrm{~s}\left(\mathrm{H}_{2} \mathrm{O}\right) / 45 \mathrm{~s}\left(\mathrm{~N}_{2}\right)$. Growth includes different regimes: growth delay (regime I), substrate inhibited growth of type II (regime II), and steady growth (regime III). The red dash line is a parabolic fit. Gray dot line represents a difference between the thickness after DEZn injection and after water injection for the chosen cycle as a function of the number of cycles.

ness jump is observed at the first cycle, then the thickness almost does not change, the average thickness slowly increases (see zoom inset, blue oval; gray line shows the average thickness for every cycle). During this growth delay, the thickness steps are not visible, then the thickness steps become visible and the step height changes at higher cycle numbers (regime II, see inset, red oval). The growth rate in regime II is not constant, a thickness S-shape curve is observed [29]. At last, the thickness increases linearly and the growth rate becomes constant (regime III, the step height is constant, green oval on Fig.2(a)).

Figure 2(b) shows the experimental growth per cycle (GPC) values as function of the number of cycles. We calculated GPC for cycle $n$ as the difference in thickness for cycle $n$ and thickness for cycle $(n-1)$. The thickness values for cycle $n$ and $(n-1)$ are the average thicknesses during $\mathrm{N}_{2}$ purge after water injection (see Figure 1).
During regime I, the GPC is constant and almost zero, except for cycle 1 (GPC is about $0.15 \mathrm{~nm} . \mathrm{cy}^{-1}$ ). Then, in regime II the GPC shows the characteristic substrate inhibited growth of type II [29], that is the GPC shows a parabolic increase, reaches a maximum, and then decreases to reach a constant value. In regime III (steady growth state) the GPC is constant.

Assuming that the $\operatorname{GPC}(n)$ curve in regime II has a parabolic increase in the beginning, we fitted the data with function $A\left(n-n_{\text {delay }}\right)^{2}$, where $\mathrm{n}_{\text {delay }}$ is the number of ALD cycles at which the parabolic GPC begins [15], and $A$ is a scale factor. The parabolic GPC fit curve (red dash line) gives the number $\mathrm{n}_{\text {delay }}=22$ cycles for the corresponding sample.

As shown in Figure 1, the layer thickness decreases after water injection, instead, the thickness obtained after the DEZn injection is barely affected. Figure 2(b) (gray dotted line) shows the difference between the thickness after DEZn injection and the thickness after water injection for each cycle. Experimental layer thickness after DEZn or water injection was calculated with the values recorded inside the $\mathrm{N}_{2}$ purge areas (see Fig. 1).

Figure 2(b) shows that this function has a value close to zero (including the first ALD cycle) in the regime I. Then in regime II, this function grows proportionally to the GPC function. In regime III, this function reaches a constant value $\left(\approx 0.15 \mathrm{~nm} . \mathrm{cy}^{-1}\right)$. This means that after the water pulse the thickness decrease (likely due to $\mathrm{C}_{2} \mathrm{H}_{5}$ ligand effusion) is constant during the steady growth state.

To study how the DEZn and water concentrations modify growth, i.e. the growth delay and steady state growth (GPC), we grew a series of samples by varying the DEZn injection time.

3.2 DEZn concentration vs. growth delay In a previous study [15], we demonstrated the effect of water concentration (by varying the water flow) on the initial stages of growth, by monitoring Zn X-ray Fluorescence (XRF) signal during $\mathrm{ZnO}$ growth on InGaAs. We showed the possibility to decrease the growth delay (number of cycles in regime I, see Fig. 2), at higher water flow.

Here, we report on the influence of DEZn molecules concentration on the growth delay. We monitored the growth by in situ ellipsometry for a series of samples with different DEZn injection times. The injection times for this series were equal to \#s(DEZn), $45 \mathrm{~s}\left(\mathrm{~N}_{2}\right), 40 \mathrm{~s}\left(\mathrm{H}_{2} \mathrm{O}\right)$ and $45 \mathrm{~s}\left(\mathrm{~N}_{2}\right)$. DEZn injection time \# from one sample to another was $1 \mathrm{~s}, 2 \mathrm{~s}, 5 \mathrm{~s}, 10 \mathrm{~s}, 20 \mathrm{~s}, 40 \mathrm{~s}$, and $80 \mathrm{~s}$. Other deposition parameters were fixed as described in Section 3.1 .

Figure S1 (see supplementary information) shows the $\mathrm{ZnO}$ thickness (a) and corresponding GPC (b) as a function of the number of cycles for different DEZn injection times (different samples).

All recorded GPC curves exhibit the same shape: a growth delay (regime I), substrate inhibited growth of type II (regime II), and steady growth (constant GPC, regime 
III). Figure S1 shows that the growth delay (regime I) is shortened while increasing the DEZn injection time. Figure 3 shows steady growth GPC (a) and $n_{\text {delay }}$ (b) as a function of DEZn injection time. The steady GPC increases for

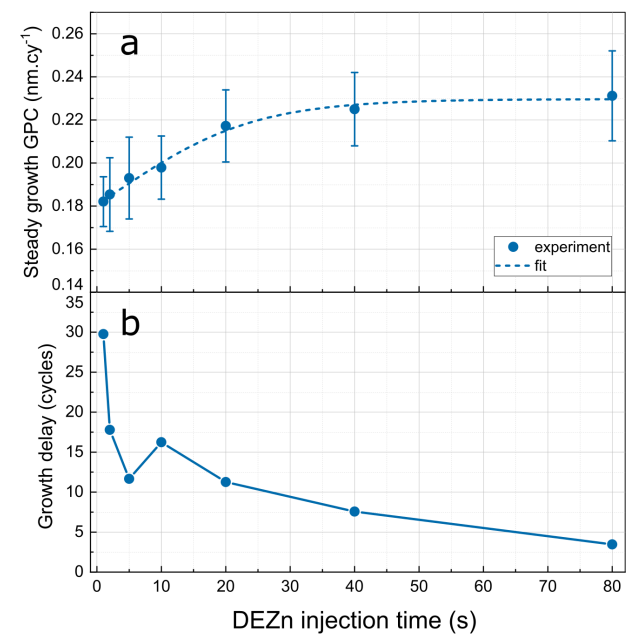

Figure 3 Steady growth GPC (a) and growth delay $\mathrm{n}_{\text {delay }}$ (b) as functiuons of DEZn injection time. Other growth parameters were fixed.

higher DEZn injection times from $0.18 \mathrm{~nm} . \mathrm{cy}^{-1}$ (for $1 \mathrm{~s}$ of DEZn injection) to $0.23 \mathrm{~nm} . \mathrm{cy}^{-1}$ (for $80 \mathrm{~s}$ of DEZn injection). First, there is a significant GPC increase for the range $1 \mathrm{~s}-20 \mathrm{~s}\left(0.18 \mathrm{~nm} \cdot \mathrm{cy}^{-1}-0.22 \mathrm{~nm} . \mathrm{cy}^{-1}\right)$, and then an asymptotic GPC increase for the range $20 \mathrm{~s}-80 \mathrm{~s}\left(0.22 \mathrm{~nm} . \mathrm{cy}^{-1}\right.$ $\left.0.23 \mathrm{~nm} . \mathrm{cy}^{-1}\right)$. The steady GPC reaches a plateau for a DEZn injection time beyond 20 s.

The opposite trend is observed for $n_{\text {delay }}$ (Fig. 3(b)). $n_{\text {delay }}$ decreases when increasing DEZn injection times from 30 cycles (1s of DEZn injection) to 3 cycles $(80 \mathrm{~s}$ of DEZn injection). For 20s-80s DEZn injection times, when steady GPC is almost constant $\left(0.22 \mathrm{~nm}^{-c y}{ }^{-1}\right.$ $\left.0.23 \mathrm{~nm}^{\mathrm{c}} \mathrm{y}^{-1}\right), \mathrm{n}_{\text {delay }}$ decreases from 11 cycles to 3 cycles. It is clear that the increase of DEZn injection time (increasing the number of DEZn molecules inside the reaction chamber) leads to the decrease of the growth delay and to have about the same steady growth rate.

3.3 Long water/DEZn pulse during cycle 1 As reported in Section 3.2, an increase of water or DEZn molecules concentration during the precursor pulse, decreases $\mathrm{n}_{\text {delay }}$. The change of substrate surface functionalization after the first cycle can lead to different $\mathrm{ZnO}$ growth behavior. To check that in the case of ZnO ALD on InGaAs, we monitored thickness in situ while injecting a long pulse of water or DEZn into the reactor at the first cycle. The main growth parameters were fixed as described in Section 1, for cycles 2-50, DEZn (resp. water) injection time was $5 \mathrm{~s}$ (resp. $40 \mathrm{~s}$ ).

Regarding the long water pulse cycle (inset of Figure 4(a)), as usual, DEZn was first injected into the reactor for $5 \mathrm{~s}$. Then, the reactor was purged with $\mathrm{N}_{2}$ during $45 \mathrm{~s}$.

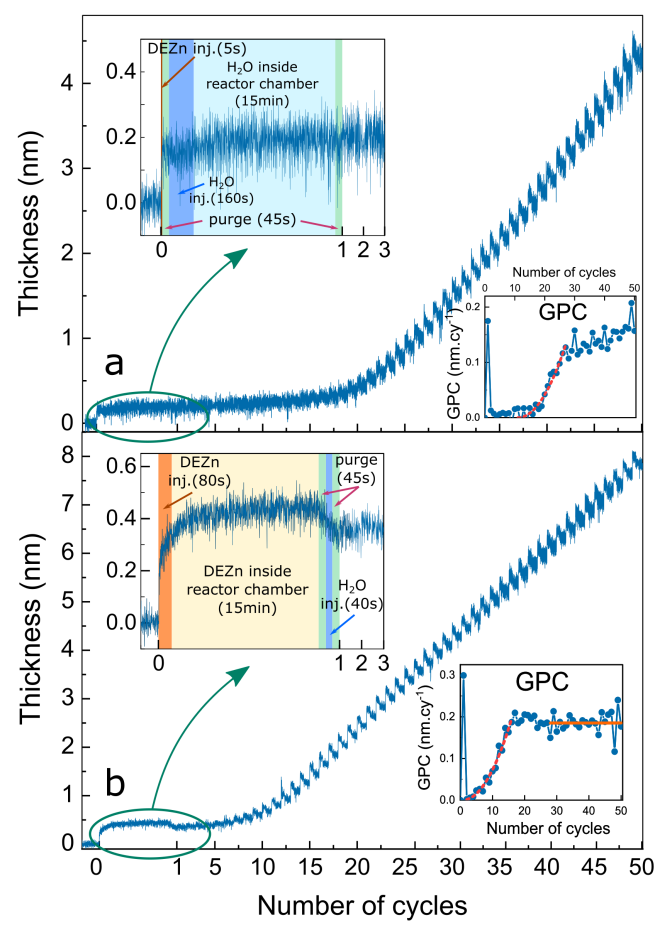

Figure 4 Long water (a) and DEZn (b) injection during the first cycle: thickness as a function of the number of cycles. Left insets: description of gas injections during first ALD cycle. Right insets: GPC as a function of the number of cycles with parabolic fits $\left(\mathrm{n}_{\text {delay }}\right.$ is 11 cycles (a) or 0 cycles (b) for long water or DEZn injection during the first ALD cycle).

After the purge, water vapor was injected into the reactor chamber during 160 s (up to 2 mbar inside the reactor chamber). Water was kept in the closed reactor chamber for 15 min, then the reactor was purged with $\mathrm{N}_{2}$ for $45 \mathrm{~s}$. For cycles 2-50, the injection times for DEZn/ $\mathrm{N}_{2} / \mathrm{H}_{2} \mathrm{O} / \mathrm{N}_{2}$ were $5 \mathrm{~s} / 45 \mathrm{~s} / 40 \mathrm{~s} / 45 \mathrm{~s}$, respectively.

Figure 4(a) shows the thickness and GPC as functions of the number of cycles measured for a long first-cycle water injection time. Despite this long time for the water to react, a growth delay is still present, $\mathrm{n}_{\text {delay }}$ is about $11 \mathrm{cy}-$ cles.

A similar experiment was performed with a long DEZn pulse at the first cycle (see inset of Figure 4(b)). A $5 \mathrm{sccm}$ flow of DEZn was injected inside the closed reactor chamber during the 80 s (to reach a 2 mbar pressure inside the reactor chamber). Then, DEZn molecules were kept inside the reactor chamber for $15 \mathrm{~min}$ to react. Then, DEZn was purged with nitrogen for $45 \mathrm{~s}$, water was injected for $40 \mathrm{~s}$, and the reactor was purged again for $45 \mathrm{~s}$. For cycles 2-50, injection times were $5 \mathrm{~s} / 45 \mathrm{~s} / 40 \mathrm{~s} / 45 \mathrm{~s}$ for $\mathrm{DEZn} / \mathrm{N}_{2} / \mathrm{H}_{2} \mathrm{O} / \mathrm{N}_{2}$, respectively.

Unlike long water pulse, a long DEZn pulse causes the suppression of the growth delay (see right inset of Fig- 
ure $4(\mathrm{~b}), n_{\text {delay }}$ is close to 0 cycles). Even though a less amount of DEZn (DEZn injection time is 5s) is injected during cycles $2-50$, there is no growth delay, the growth starts immediately with regime II.

To check a possible change of surface morphology, we performed AFM of the InGaAs surface after $\mathrm{HCl}$ cleaning (Figure 5(a)) and $1 \mathrm{ZnO}$ ALD cycle comprising a long DEZn pulse (Figure 5(b)). The dotted lines on the AFM

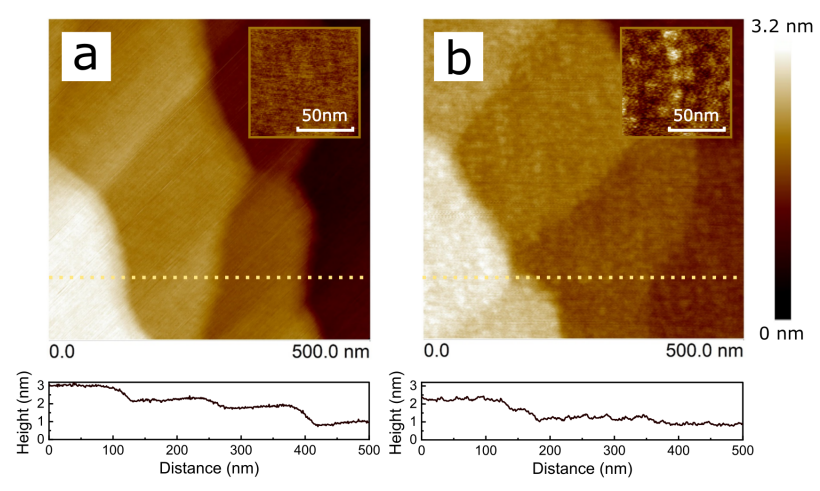

Figure 5 Atomic Force Microscopy (AFM) images obtained for InGaAs surface after $\mathrm{HCl}$ treatment (a) and InGaAs surface after one ALD cycle with a long DEZn injection (b). Yellow dotted lines on the images shows the positions of the cross lines (corresponding cross lines shown below the AFM images).

images indicate the position of surface cross lines, shown under the AFM images. InGaAs surface is presented by atomically flat terraces, the InGaAs roughness (RMS) on the terraces is about $0.05 \mathrm{~nm}$, and the RMS of the terraces is $0.3 \mathrm{~nm}$. The plot above Fig. 5(a) shows the cross line of the InGaAs terraces after $\mathrm{HCl}$ cleaning. After $1 \mathrm{ZnO}$ ALD cycle, including the long DEZn pulse, surface roughness (RMS) increases up to $0.09 \mathrm{~nm}$ (see Fig. 5(b)).

4 Discussion $\mathrm{ZnO}$ growth on either InGaAs or $\mathrm{ZnO}$ surface is very different $[15,16]$. ZnO ALD on $\mathrm{ZnO}$ has been the subject of experimental works [30], and more recently of DFT and Monte Carlo simulations [31-36]. Besides, $\mathrm{ZnO}$ surface reactivity, which depends on the surface polarity and reconstruction, has been studied [37, 38]. In the present study, we focused on the control of the growth delay during $\mathrm{ZnO}$ ALD on InGaAs, by varying the injection time of precursors. During the growth delay (regime I, inset of Fig. 2(a)), the GPC is 30-50 times smaller (about $0.005 \mathrm{~nm} \mathrm{cy}^{-1}$ ) than the steady growth GPC (0.18-0.23nm.cy ${ }^{-1}$, at a substrate temperature equal to $\left.120^{\circ} \mathrm{C}\right)$. However, the slight thickness increase is a clear indication of the presence of chemical reactions occurring on the InGaAs surface.

In Figure 2 we observe that the GPC for the first ALD cycle is higher than for cycles in the range [2-n delay $]$. During the first ALD cycles, DEZn reacts with active surface sites, present on InGaAs surface, and leads to higher GPC value than those observed in the next cycles. Thus, we hypothesized that a long time left for water or DEZn to react (or higher concentration of water or DEZn) could increase the number of active surface sites available for the next cycles, and could shorten the growth delay.

We found that after a long water injection time at the first cycle (see Section 3.3, Fig. 4(a)), $\mathrm{n}_{\text {delay }}$ is still 12 cycles, the same value as observed in the case of usual water injection time (all other parameters being identical). Evidently, a long interaction with water does not lead to a significant increase of active surface sites on InGaAs $(\mathrm{OH}-$ groups, water molecules) for a reaction with DEZn.

Regarding the DEZn effect, we observed that by increasing DEZn pulse duration (i.e. the DEZn concentration inside the closed reactor chamber), the growth delay is shortened. Besides, by increasing the DEZn injection time from 20 s to 80 s, the steady growth GPC values are almost the same $\left(0.22-0.23 \mathrm{~nm} . \mathrm{cy}^{-1}\right.$, Fig. 3(a)), whereas the number of cycles, $\mathrm{n}_{\text {delay }}$, decreases from 11 cycles down to 3 cycles. The same effect was observed for a long DEZn injection during the first cycle, $\mathrm{n}_{\text {delay }}$ became close to 0 cycles (inset of Fig. 4(b)). Both ways for DEZn injection (80s of DEZn injection every cycle or long DEZn injection during the first cycle) leads to the disappearance of regime I. This means that a long interaction of DEZn with InGaAs surface renders InGaAs surface more reactive.

AFM image (Fig. 5), obtained after one ALD cycle comprising a long DEZn injection, shows that the morphology of InGaAs surface has changed in comparison with InGaAs cleaned surface. Small nuclei or islands have appeared.

One possible process during the long DEZn injection can be a reaction between monoethylzinc (MEZn) on the InGaAs sufrace with DEZn molecule. Weckman et al. [31] demonstrated that this type of reaction can lead to the formation of additional bare $\mathrm{Zn}$ atoms and products of the reaction (organic molecules). Then, this $\mathrm{Zn}$ atom can adsorb more water molecules, leading to a growth rate increase.

More investigations are needed to determine the chemical reactions at play in between DEZn, water, and InGaAs surface at the early stage of growth of $\mathrm{ZnO}$ by ALD.

Acknowledgements E.V. Skopin was supported by ANR project ANR-18-CE09-0031-03 and the LabEx Minos ANR-10LABX-55-01. Financial support by the Centre of Excellence of Multifunctional Architectured Materials (Labex CEMAM) ANR10-LABX-44-01 for implementing the ellipsometer is gratefully acknowledged. We acknowledge D. De Barros for engineering assistance. We thank laboratory of Science et Ingénierie des Matériaux et Procédés (SIMAP, Grenoble-INP, Grenoble (France)) for technical assistance.

\section{References}

[1] J. A. Del Alamo, Nature 479(7373), 317 (2011).

[2] H. Ishikawa, Applied physics letters 63(6), 712-714 (1993).

[3] J. C. Woolley, M. B. Thomas, and A. G. Thompson, Canadian Journal of Physics 46(2), 157-159 (1968). 
[4] J. W. Wagner, Journal of The Electrochemical Society 117(9), 1193-1196 (1970).

[5] M. Heyns and W. Tsai, Mrs bulletin 34(7), 485-492 (2009).

[6] A. Sonnet, R. Galatage, P. Hurley, E. Pelucchi, K. Thomas, A. Gocalinska, J. Huang, N. Goel, G. Bersuker, W. Kirk et al., Microelectronic Engineering 88(7), 1083-1086 (2011).

[7] M. Paladugu, C. Merckling, R. Loo, O. Richard, H. Bender, J. Dekoster, W. Vandervorst, M. Caymax, and M. Heyns, Crystal Growth \& Design 12(10), 4696-4702 (2012).

[8] J. Robertson, Journal of Vacuum Science \& Technology A: Vacuum, Surfaces, and Films 31(5), 050821 (2013).

[9] D. Connelly, C. Faulkner, D. Grupp, and J. Harris, IEEE Transactions on Nanotechnology 3(1), 98-104 (2004).

[10] M. H. Liao and C. Lien, AIP Advances 5(5), 057117 (2015).

[11] A. Agrawal, N. Shukla, K. Ahmed, and S. Datta, Applied Physics Letters 101(4), 042108 (2012).

[12] P. O. Oviroh, R. Akbarzadeh, D. Pan, R. A. M. Coetzee, and T.C. Jen, Science and technology of advanced materials 20(1), 465-496 (2019).

[13] S. M. George, Chemical reviews 110(1), 111-131 (2009).

[14] V. Miikkulainen, M. Leskelä, M. Ritala, and R. L. Puurunen, Journal of Applied Physics 113(2), 2 (2013).

[15] E. V. Skopin, L. Rapenne, H. Roussel, J. L. Deschanvres, E. Blanquet, G. Ciatto, D.D. Fong, M. I. Richard, and H. Renevier, Nanoscale 10, 11585-11596 (2018).

[16] E. V. Skopin, L. Rapenne, J. L. Deschanvres, E. Blanquet, G. Ciatto, L. Pithan, D. D. Fong, M. I. Richard, and H. Renevier, submitted (2019).

[17] E. Langereis, S. Heil, H. Knoops, W. Keuning, M. Van de Sanden, and W. Kessels, Journal of Physics D: Applied Physics 42(7), 073001 (2009).

[18] R. Boichot, L. Tian, M. I. Richard, A. Crisci, A. Chaker, V. Cantelli, S. Coindeau, S. Lay, T. Ouled, C. Guichet et al., Chemistry of Materials 28(2), 592-600 (2016).

[19] M. H. Chu, L. Tian, A. Chaker, V. Cantelli, T. Ouled, R. Boichot, A. Crisci, S. Lay, M. I. Richard, O. Thomas et al., Crystal Growth \& Design 16(9), 5339-5348 (2016).

[20] M. H. Chu, L. Tian, A. Chaker, E. Skopin, V. Cantelli, T. Ouled, R. Boichot, A. Crisci, S. Lay, M. I. Richard et al., Journal of Electronic Materials 46(6), 3512-3517 (2017).

[21] Y. Sun, P. Pianetta, P. T. Chen, M. Kobayashi, Y. Nishi, N. Goel, M. Garner, and W. Tsai, Applied Physics Letters 93(19), 194103 (2008).

[22] FilmSenceLLC, FS-1 manual2015).

[23] E. Guziewicz, I. Kowalik, M. Godlewski, K. Kopalko, V. Osinniy, A. Wójcik, S. Yatsunenko, E. Łusakowska, W. Paszkowicz, and M. Guziewicz, Journal of Applied Physics 103(3), 033515 (2008).

[24] Z. Gao, F. Wu, Y. Myung, R. Fei, R. Kanjolia, L. Yang, and P. Banerjee, Journal of Vacuum Science \& Technology A: Vacuum, Surfaces, and Films 34(1), 01A143 (2016).

[25] H. Fujiwara, Spectroscopic ellipsometry: principles and applications (John Wiley \& Sons, 2007).

[26] D. E. Aspnes and A. Studna, Physical review B 27(2), 985 (1983).

[27] S. Adachi, Journal of Applied Physics 66(12), 6030-6040 (1989).
[28] W. Bond, Journal of Applied Physics 36(5), 1674-1677 (1965).

[29] R. L. Puurunen and W. Vandervorst, Journal of Applied Physics 96(12), 7686-7695 (2004).

[30] T. Tynell and M. Karppinen, Semiconductor Science and Technology 29(4), 043001 (2014).

[31] T. Weckman and K. Laasonen, The Journal of Physical Chemistry C 120(38), 21460-21471 (2016).

[32] T. Weckman, M. Shirazi, S. D. Elliott, and K. Laasonen, The Journal of Physical Chemistry C 122(47), 2704427058 (2018).

[33] T. Weckman and K. Laasonen, The Journal of Physical Chemistry C 122(14), 7685-7694 (2018).

[34] A. Afshar and K.C. Cadien, Applied Physics Letters 103(25), 251906 (2013).

[35] S. Patwardhan, D. H. Cao, G. C. Schatz, and A. B. Martinson, ACS Applied Energy Materials (2019).

[36] S. Kim, S. Lee, S. Y. Ham, D. H. Ko, S. Shin, Z. Jin, and Y. S. Min, Applied Surface Science 469, 804-810 (2019).

[37] S. Chamberlin, C. Hirschmugl, S. King, H. Poon, and D. Saldin, Physical Review B 84(7), 075437 (2011).

[38] S. King, S. Parihar, K. Pradhan, H. T. Johnson-Steigelman, and P. Lyman, Surface Science 602(22), L131-L134 (2008). 


\section{Graphical Table of Contents}

GTOC image:

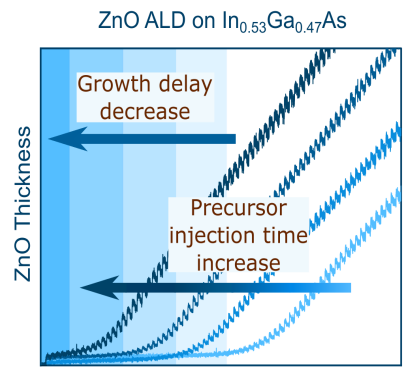

Number of ALD cycles

Your article will be published with a Graphical Abstract in the table of contents. Please send a suggestion for an image (preferably full colour, size $4 \mathrm{~cm} \mathrm{x} 4 \mathrm{~cm}$ ). It may be specifically designed for the purpose, but should not show too many details or consist of several parts. Enclose a short descriptive and popular text on the general aim and value of your paper which may serve as an 'appetizer' for the readers (40-70 words, not a Figure caption, not the abstract text). 